\title{
Proximal tibiofibular dislocation accompanied by bucket-handle meniscal tear: Case report
}

\author{
Bülent Tanrıverdi, MD®D, Ersin Erçin, MD(D, Erdem Edipoğlu, MD(D), Cemal Kural, MD(D) \\ Department of Orthopedics and Traumatology, University of Health Sciences, \\ Bakırköy Dr. Sadi Konuk Training and Research Hospital, Istanbul, Turkey
}

The proximal tibiofibular joint is a synovial joint where the fibular head articulates with the lateral condyle of the tibia. The joint capsule, the anterior, and the posterior tibiofibular ligaments provide stabilization. ${ }^{[1]}$ Proximal tibiofibular dislocation (PTFD) is a rare injury and can occur in several types of sports and motor accidents. ${ }^{[1,2]}$ The dislocation may be seen as isolated or in combination with other injuries. ${ }^{[3]}$ Ogden $^{[3]}$ identified four types of injury (Table I).

Clinically, the dislocation presents with pain, swelling, and deformity at the lateral side of the knee joint. The patient may have difficulty bearing weight on the affected lower extremity. The fibular head may be seen displaced laterally with enlargement of the interosseous distance on radiographs. Comparative radiographs and computed tomography (CT) can assist in challenging diagnoses.

Received: October 01, 2019

Accepted: December, 2019

Published online: September 11, 2020

Correspondence: Bülent Tanrıverdi, MD. SBÜ Bakırköy Dr. Sadi Konuk Egitim ve Araştırma Hastanesi, Ortopedi ve Travmatoloji Kliniği 34147 Bakırköy, İstanbul, Türkiye.

E-mail: drbulenttanriverdi@gmail.com

Doi: $10.5606 /$ ehc. 2020.71630

Presented at the $29^{\text {th }}$ Turkish National Congress of Turkish Orthopedics and Traumatology, (October 22-27, 2019, Belek, Antalya, Turkey).

Citation: Tanrıverdi B, Erçin E, Edipoğlu E, Kurala C. Proximal tibiofibular dislocation accompanied by bucket-handle meniscal tear: Case report. Jt Dis Relat Surg 2020;31(3):634-638.

(02020 All right reserved by the Turkish Joint Diseases Foundation

This is an open access article under the terms of the Creative Commons Attribution-NonCommercial License, which permits use, distribution and reproduction in any medium, provided the original work is properly cited and is not used for commercial purposes (http://creativecommons.org/licenses/by-nc/4.0/).

\section{ABSTRACT}

Proximal tibiofibular dislocation (PTFD) is a rare injury. In this article, we report a case of a PTFD, complicated with an intraarticular injury, a bucket-handle tear of the lateral meniscus. A 37-year-old male patient presented to the emergency department with pain and swelling on the lateral side of his right knee due to lateral trauma to the fibula during external rotation of the leg while his foot was on the ground. Closed reduction was performed under sedation. The lateral meniscus was repaired, and the fibular head was fixed with a cannulated screw. The patient had no pain in the tibiofibular joint after eight weeks postoperatively. Results of magnetic resonance imaging for the diagnosis of PTFD should be kept in mind during the presentation of sports trauma patients that experience difficulty in bearing weight on the affected extremity.

Keywords: Dislocation, magnetic resonance imaging, meniscal tear, proximal tibiofibular joint.

In this article, we report a case of PTFD, complicated with an intraarticular injury, a buckethandle tear of the lateral meniscus. To our knowledge, this is the first report in the literature that presents both injuries concomitantly.

\section{CASE REPORT}

A 40-year-old male patient presented to the emergency ward with pain and swelling on the lateral aspect of the right knee due to lateral trauma to the fibula during external rotation of the leg with his foot on the ground while playing football. Physical examination revealed minimal effusion in the knee joint, a prominent fibular head, and pain in the proximal tibiofibular joint. The patient had difficulty bearing weight on the affected extremity. Knee range of motion was measured as $0^{\circ}-135^{\circ}$. The dorsalis pedis and posterior tibial artery pulses were evaluated as palpable. No peroneal nerve damage was detected. Ankle dorsiflexion and plantar 


\section{TABLE I}

Ogden classification of proximal tibiofibular dislocations

\section{Type I Subluxation}

Type II Anterolateral dislocation*

Type III Posteromedial dislocation

Type IV Superior dislocation

* Most common form.

flexion were painless, and full range of motion was confirmed. A written informed consent was obtained from the patient.

Anterolateral dislocation of the fibular head from the tibiofibular joint was detected on the anteroposterior and lateral radiographs (Figure 1). Computed tomography confirmed the diagnosis. No osseous pathology was detected.

After the physical examination, radiography, and $\mathrm{CT}$, axial traction and internal rotation were applied under sedation, and the fibular head was manipulated to provide closed reduction. Deformity disappeared after reduction (Figure 2). The fibular head was more mobile compared to the contralateral knee, which was considered as instability. After reduction, the distal neurovascular examination was normal, and there was no pain; then, long-leg plaster splint was applied. The magnetic resonance imaging (MRI) scans showed that the proximal tibiofibular joint was reduced. Besides, the presence of soft tissue edema around the knee joint, hematoma, joint capsule, and tibiofibular ligament tears were detected. A bucket-handle lateral meniscal tear was also detected as an intraarticular pathology (Figure 3). Surgery was planned, and the patient was operated due to instability and the bucket-handle meniscal tear.

The arthroscopy of the knee revealed that the medial meniscus was intact. However, a big buckethandle tear was detected in the lateral meniscus. The popliteus tendon was also intact. The lateral meniscus was repaired all-inside with five vertical mattress sutures, and then the meniscus was found to be reduced. Then, a curved incision was performed for the proximal fibula. The lateral collateral ligament was intact but slightly elongated. The fibular head, which was unstable in the proximal tibiofibular joint, was reduced, and fixation was performed under fluoroscopy using one cannulated screw (Figure 4). Subsequently, a long-leg plaster splint was applied. We did not detect peroneal nerve damage after surgery.

The sutures and the plaster splint were removed in the postoperative second week. The patient had full range of motion of the knee, with mild pain at the surgery site.

At the end of the eighth postoperative week, the patient had no pain in the tibiofibular joint. The knee flexion and extension movements were found to be between $0^{\circ}-135^{\circ}$ and equal to the contralateral knee. The patient was allowed full weight-bearing.

\section{DISCUSSION}

Proximal tibiofibular dislocation is a rare injury, reported in a limited number of articles. In our case, type II dislocation, the most common type, accompanied by a bucket-handle meniscal tear, was detected. To the best of our knowledge, this is the

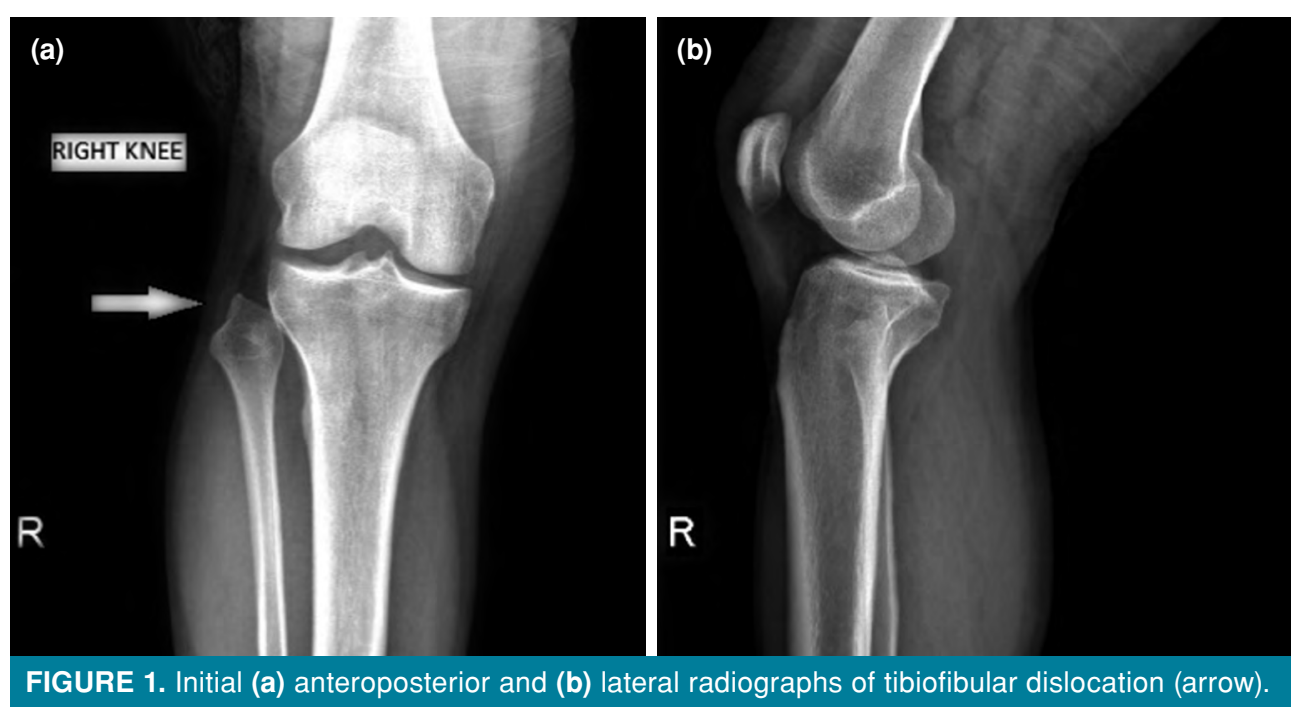



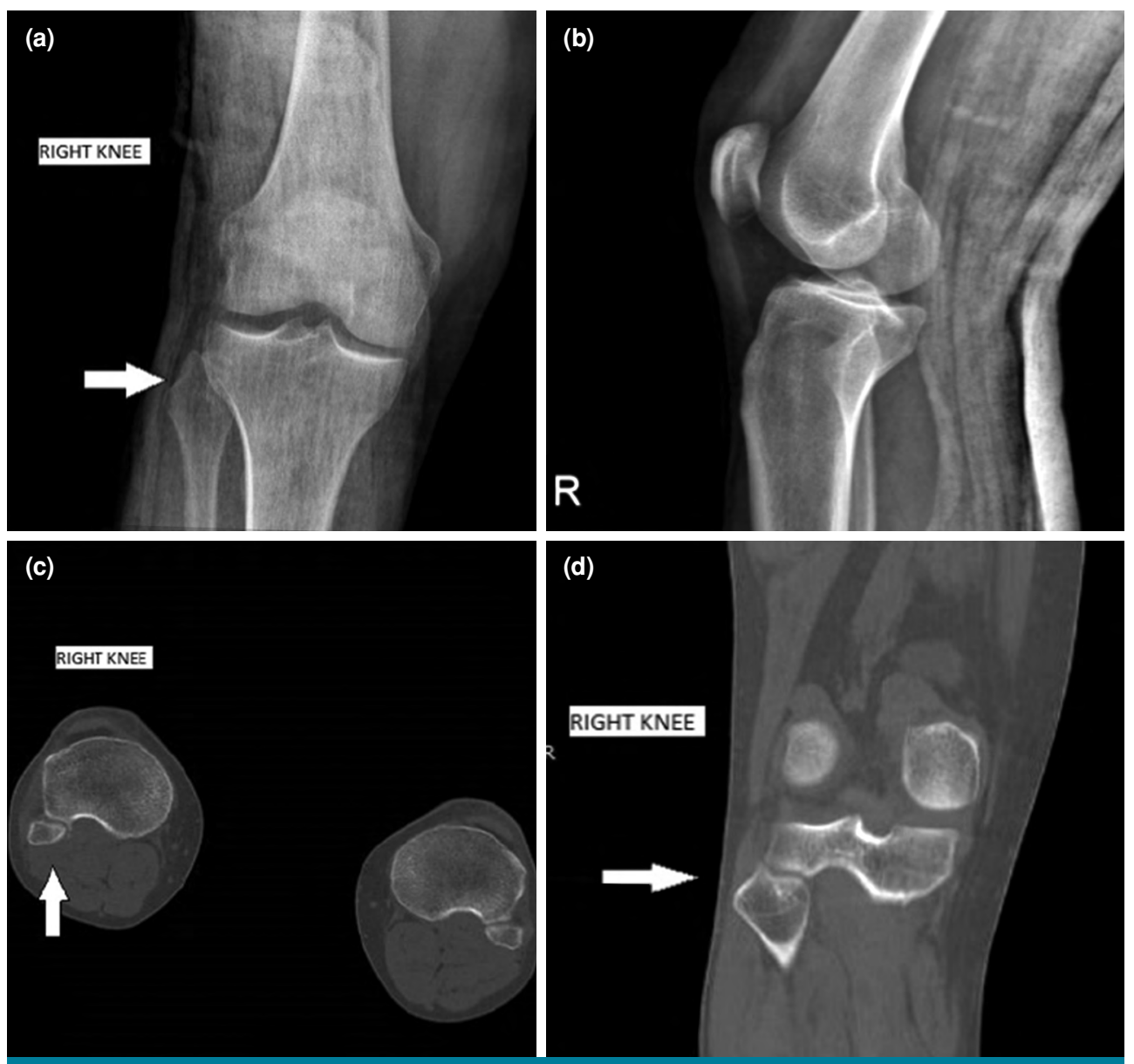

FIGURE 2. Post-reduction (a) anteroposterior and (b) lateral radiographs of tibiofibular dislocation (arrow). (c) Axial and (d) coronal computed tomography scans of right knee show reduced proximal tibiofibular joint (arrows).

first publication to indicate the association of these two injuries. ${ }^{[4]}$

A PTFD should be suspected in patients who have lateral knee pain and difficulty in stepping with the involved extremity. ${ }^{[5]}$ Patients with tibiofibular joint dislocation often present with lateral knee pain, affected knee movements that are often normal, and without intraarticular effusion. ${ }^{[6,7]}$ In our case,
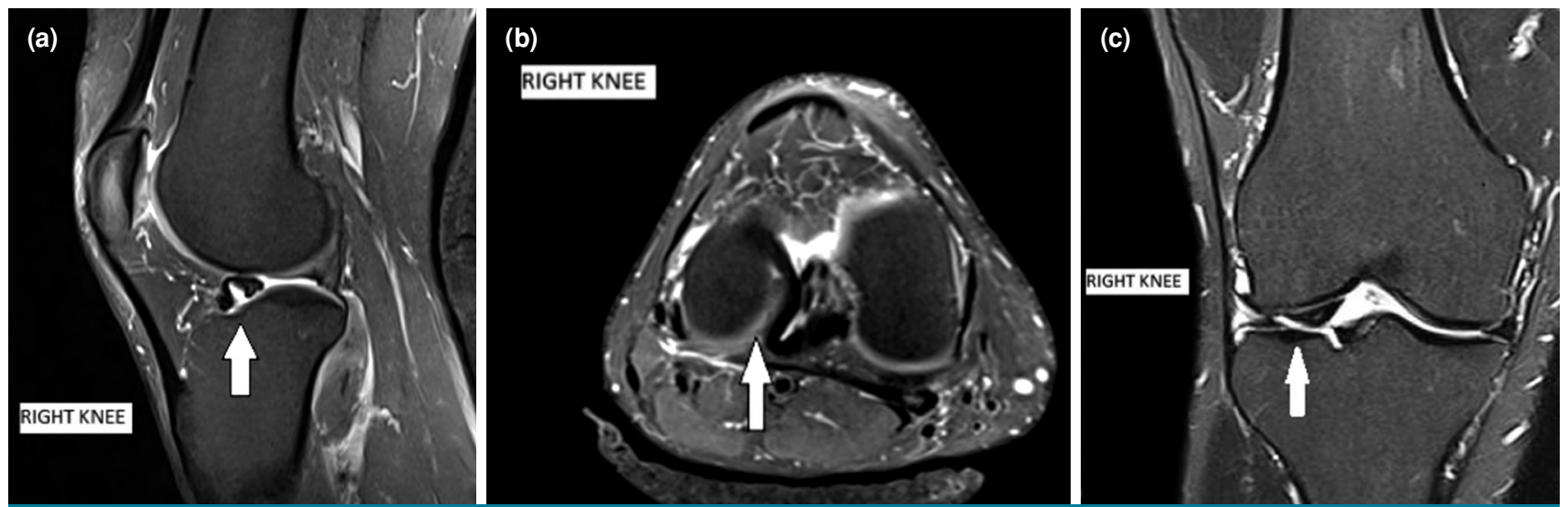

FIGURE 3. (a) Sagittal, (b) axial, and (c) coronal T2 magnetic resonance images show bucket-handle meniscal tear accompanying proximal tibiofibular dislocation (arrows). 


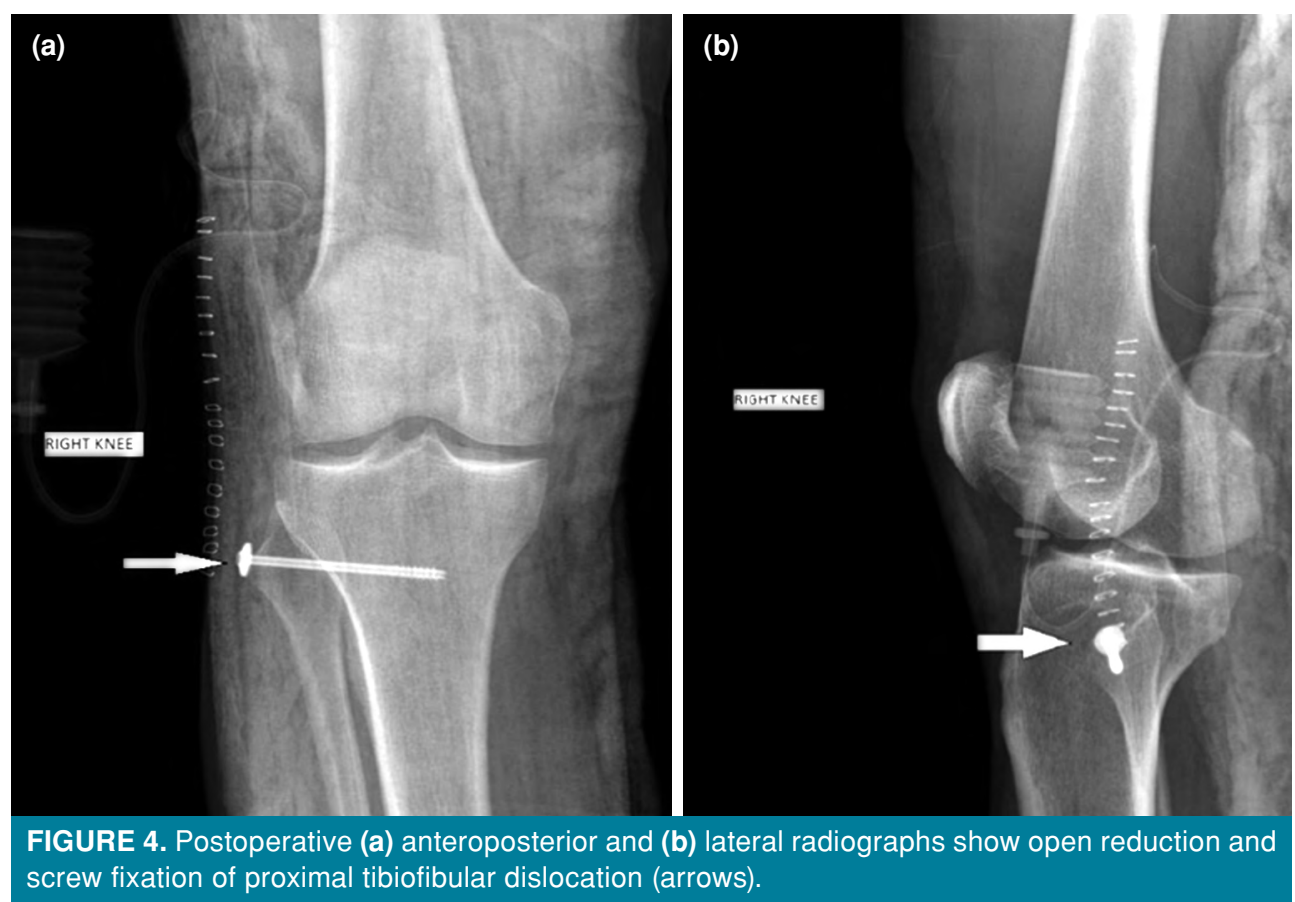

the knee movements were found normal in the first examination, and there was minimal intraarticular effusion. Delayed or wrongful diagnosis and inappropriate treatment of PTFDs may lead to chronic pain, difficulty in weight-bearing, and decreased sportive performance. ${ }^{[8]}$

Proximal tibiofibular joint dislocation can usually be reduced by flexing the knee, and a "pop" sound can be heard or felt, ${ }^{[7]}$ with sudden relief of pain. The patient is then mobilized without bearing weight on the involved extremity. Allowing weight-bearing is decided during the follow-up. ${ }^{[2]}$ We achieved closed reduction with manipulation in our patient, and the deformity disappeared after reduction.

There are few publications on intraarticular pathologies regarding PTFDs. After this injury, it is highly probable that the diagnosis of intraarticular pathologies cannot be established. The accuracy of the diagnosis rate with direct radiographs is $73 \%$, whereas the rate increases to $81 \%$ with the inclusion of comparison views. ${ }^{[9]}$ Krukhaug and Schrama ${ }^{[10]}$ suggested that CT was the best method in case of any doubt about the diagnosis. In our case, the diagnosis of the bucket-handle meniscal tear concomitant with this dislocation could not be established by examination but by MRI. In this respect, we believe that MRI is essential in detecting the intraarticular pathologies in such dislocations formed by a similar mechanism.
Many methods of treatment and follow-up have been reported in the literature. Nieuwe Weme et al. ${ }^{[1]}$ applied three layers of bandage for one week after closed reduction and allowed for early mobilization. The authors reported that the patient had no complaints during the sixth-month follow-up. Reynolds et al. ${ }^{[12]}$ operated on a professional ice hockey player whose tibiofibular dislocation was spontaneously reduced on the $12^{\text {th }}$ day due to ongoing pain and instability. The authors reported that they used a $3.5 \mathrm{~mm}$ cortical screw for fixation of the PTFD. Krukhaug and Schrama ${ }^{[10]}$ suggested that internal fixation was required in case of instability after reduction since they performed fixation in one patient using a screw, which they removed six weeks later. In another study, Okoroha et al. ${ }^{[13]}$ treated their PTFD case with syndesmotic suture buttons. According to the authors, this method is less rigid, biomechanically more appropriate, and results in a lower incidence of implant removal. In our case, we operated the patient due to a meniscal tear and instability of the tibiofibular joint. The PTFD was treated with open reduction and fixed with a screw, and the meniscal tear was repaired using sutures. The patient had no history of knee complaints in the anamnesis, and findings such as the fresh appearance of the ruptured area during surgery showed that the bucket-handle meniscal tear was associated with this injury. We concluded that the external rotation of the knee caused the injury while the foot was on the 
ground during the trauma. We also believe that, if instability of the proximal tibiofibular joint persists after reduction, open reduction and fixation will be necessary to regain stability. Also, visual evaluation of the soft tissues and ligaments around the joints may be possible, while fixing the joint.

The prevalence of peroneal nerve injury in tibiofibular joint dislocations may be as high as 5\%. ${ }^{[14]}$ This injury is most commonly associated with superior dislocation of the joint. ${ }^{[3]}$ In their study, where they evaluated three patients, Krukhaug and Schrama ${ }^{[10]}$ reported that the peroneal nerve was unaffected. In our case, we did not detect any peroneal nerve damage before or after reduction and after surgery.

In conclusion, the diagnosis of PTFD may be difficult in the emergency department, and advanced imaging methods may be required. Most of the PTFDs can be reduced with closed reduction and treated conservatively. However, meniscus and soft tissue injuries may accompany the dislocation. Therefore, we believe that MRI should be considered as an essential part of the diagnosis in PTFD.

\section{Declaration of conflicting interests}

The authors declared no conflicts of interest with respect to the authorship and/or publication of this article.

\section{Funding}

The authors received no financial support for the research and/or authorship of this article.

\section{REFERENCES}

1. Daniel JP. Knee and Lower Leg. In: Walls RM, Hockberger RS, Gausche-Hill M, editors. Rosen's Emergency Medicine: Concepts and Clinical Practise. Philadelphia: Elsevier; 2018. p. 614-33.
2. Iosifidis MI, Giannoulis I, Tsarouhas A, Traios S. Isolated acute dislocation of the proximal tibiofibular joint. Orthopedics 2008;31:605.

3. Ogden JA. Subluxation and dislocation of the proximal tibiofibular joint. J Bone Joint Surg [Am] 1974;56:145-54.

4. Atik OŞ. Which articles do we prefer to publish? Eklem Hastalik Cerrahisi 2018;29:1.

5. Chiu C, Sheele JM. Isolated Proximal Tibiofibular Dislocation during Soccer. Case Rep Emerg Med 2015;2015:657581.

6. Veerappa LA, Gopalakrishna C. Traumatic proximal tibiofibular dislocation with neurovascular injury. Indian J Orthop 2012;46:585-8.

7. Camarda L, Abruzzese A, D'Arienzo M. Proximal Tibiofibular Joint Reconstruction With Autogenous Semitendinosus Tendon Graft. Techniques in Orthopaedics 2013;28:269-72.

8. Crothers OD, Johnson JT. Isolated acute dislocation of the proximal tibiofibular joint. Case report. J Bone Joint Surg [Am] 1973;55:181-3.

9. Keogh P, Masterson E, Murphy B, McCoy CT, Gibney RG, Kelly E. The role of radiography and computed tomography in the diagnosis of acute dislocation of the proximal tibiofibular joint. Br J Radiol 1993;66:108-11.

10. Krukhaug Y, Schrama JC. Acute traumatic proximal tibiofibular dislocation: Treatment of three cases. J Orthop Case Rep 2019;9:98-101.

11. Nieuwe Weme RA, Somford MP, Schepers T. Proximal tibiofibular dislocation: a case report and review of literature. Strategies Trauma Limb Reconstr 2014;9:185-9.

12. Reynolds AW, Bhat SB, Stull JD, Krieg JC. Case report of an isolated proximal tibiofibular joint dislocation in a professional ice hockey player. J Orthop Case Rep 2018;8:93-95.

13. Okoroha KR, Mahan MC, Matar R, Khalil LS, Brand JP, Guthrie ST. Proximal tibiofibular dislocation repaired with syndesmotic suture buttons: A case report. J Orthop Case Rep 2018;8:82-5.

14. Bond MC. Knee. In: Sherman SC, editor. Simon's Emergency Orthopedics. New York: McGraw-Hill; 2015. p. $453-505$. 